\title{
Recommendation of RILEM TC 232-TDT: test methods and design of textile reinforced concrete
}

\section{Uniaxial tensile test: test method to determine the load bearing behavior of tensile specimens made of textile reinforced concrete}

\author{
RILEM Technical Committee (Wolfgang Brameshuber)
}

Received: 19 November 2015/ Accepted: 2 March 2016/Published online: 4 May 2016

(C) RILEM 2016

\section{Introduction}

Textile reinforced concrete (TRC) is a high performance cementitious composite using straight and parallel aligned fibers of suitable materials, e.g. ARglass and carbon, as continuous reinforcement in form of textiles. Textile reinforced concrete is usually used for thin concrete elements or as strengthening layers for concrete structures. Textile reinforced concrete shows a multi linear stress-strain-behavior with three distinct stages (uncracked, multiple cracking, cracking completed). The crack formation in textile reinforced concrete is significantly finer than in customary reinforced concrete. Therefore, not only the tensile

TC Membership:

Chairman: W. Brameshuber, Germany

Secretary M. Hinzen, Germany

Members A. Dubey, USA; A. Peled, Israel; B. Mobasher, USA; A. Bentur, Israel; C. Aldea, USA; F. Silva, Brasil; J. Hegger, Germany; T. Gries, Germany; J. Wastiels, Belgium; K. Malaga, Sweden; C. Papanicolaou, Greece; L. Taerwe, Belgium; M. Curbach, Germany; V. Mechtcherine, Germany; A. Naaman, USA; J. Orlowsky, Germany; P. Hamelin, France H.-W. Reinhardt, Germany; S. Shah, USA; R. Toledo, Brasil; T Triantafillou, Greece; A. Larbi, France; D. Garcia, Spain; L. Garmendia, Spain; S. Gopinath, India; F. Jesse, Germany.

RILEM Technical Committee 232-TDT

(Wolfgang Brameshuber) $(\square)$

RWTH Aachen University, Aachen, Germany

e-mail: brameshuber@ibac.rwth-aachen.de strength of the concrete but also the total tensile load bearing behavior of the composite material textile reinforced concrete is of importance.

The uniaxial tensile test presented here is a test method to determine the load bearing behavior of tensile specimens made of TRC. Bond characteristics of textile reinforcement can not be derived from this tensile test since this information could only be derived indirectly from cracking patterns. However, in textile reinforced concrete cracking is mainly controlled by transverse fibers which are typically present in textile reinforcement. For bond properties reference is given to the RILEM recommendation TDT A.2 (pull-out).

\section{Scope}

It is the aim of this recommendation to describe a standardized uniaxial tensile test method to determine the load bearing behavior of tensile specimens made of TRC. This recommendation presents a test method for measuring the load-deformation behavior of textile reinforced concrete under uniaxial tensile load with fibers aligned parallel to the loading direction. The strength of the textile, the first crack stress of the concrete as well as the stress-strain curve of the composite specimen which are necessary for the design of textile reinforced concrete can be determined from the test data. The recommendation is only valid for quasistatic testing. The recommendation is 
only valid for quasistatic testing. Definitions for e.g. textile, fabric, etc. are given in [1].

\section{Referenced standards}

ISO

9513:1999:

Metallic materials-Calibration of

ISO extensometers used in uniaxial testing.

7500-1:2004: static uniaxial testing machines_-Part 1:

Tension/compression testing machines-Verification and calibration of the force-measuring system.

\section{Definitions}

1. A tensile specimen for textile reinforced concrete is preferred to have a length to width ratio of at least 5:1 as it is designed for the measuring of elongations and crack formation.

2. Fine-grained concrete that is used in textile reinforced concrete has similar characteristics to mortar. Its aggregate usually has a grain size up to $4 \mathrm{~mm}$.

3. The first crack stress describes the stress level related to the LOP (loss of proportionality) of the stress-strain curve.

4. Textiles are manufactured products made from fibers and from yarns.

5. The laminating technique is applied to no-slump concretes. Here, the test specimens are manufactured in layers of concrete and textile fabrics.

\section{Test specimen}

\subsection{Geometry}

The minimum length of the specimen is $500 \mathrm{~mm}$, the minimum width is $60 \mathrm{~mm}$ in the measuring area. The specimen must have a length to width ratio of at least $5: 1$. Depending on the number of textile layers, the thickness may vary but must not be less than $6 \mathrm{~mm}$. The measuring length is at least $200 \mathrm{~mm}$. The direction of fibers intended to be evaluated must be aligned parallel to the longitudinal specimen axis and must be arranged symmetric to the specimen width. With respect to the thickness the fibers should be arranged symmetrically. A minimum reinforcement ratio leading to a strain-hardening behavior has to be ensured.

The specimen has a rectangular shape and can either be manufactured or cut from prefabricated textile reinforced concrete elements. Minimum specimen dimensions and shape are shown in Fig. 1. For larger specimens or for specimens with textile fabrics exhibiting low bond to the matrix and, consequently, large anchorage length the load introduction length of $125 \mathrm{~mm}$ can be increased. The associated test setup with fixed anchorage length is shown in Fig. 2. Optional test setup with variable textile anchorage length, independent on the clamping length is shown in Fig. 3. " $\mathrm{H}$ " stands for the perpendicular load for fixing the specimen, " $L_{\mathrm{A}}$ " stands for the anchorage length and " $L_{\mathrm{C}}$ " for the clamping length.

\subsection{Curing of test specimens}

Test specimens are stored in laboratory climate at least 7 days before testing.

\section{Test equipment}

\subsection{Climate}

The tests are carried out in laboratory climate.

\subsection{Testing machine}

The testing machine shall be of any type sufficient to provide the required load and the rate of crosshead movement prescribed. It shall have been verified to have an accuracy of the extensometers in agreement with ISO 9513 and the force measuring system in agreement with ISO 7500-1.

\subsection{Test setup}

The specimen (Fig. 1) is clamped between sufficiently stiff steel plates with a rubber sheet (neoprene or similar) in between. The plates must have at least a rotational capacity in the plane of the specimen. The load is transferred to the specimen by friction (Fig. 2). 
Fig. 1 Rectangular specimen [2]

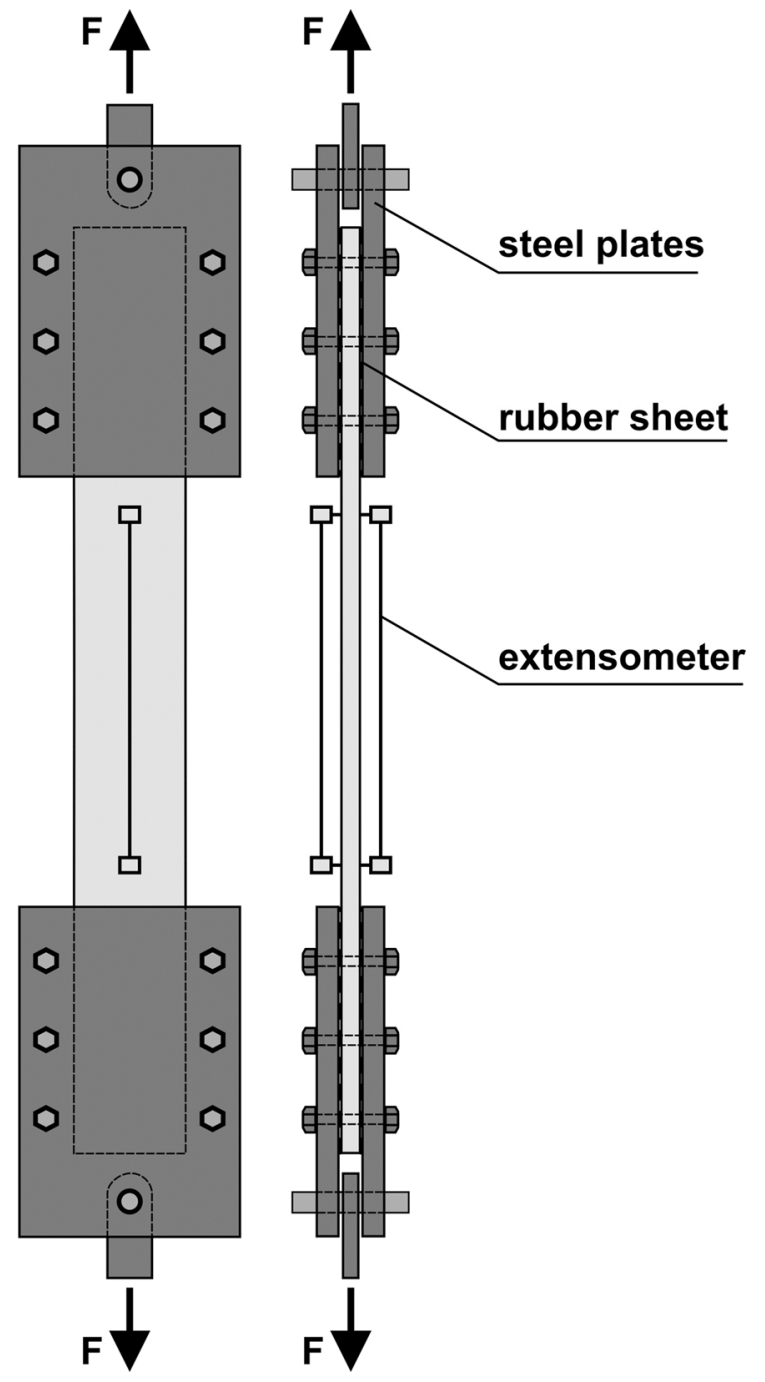

Fig. 2 Test setup [2]

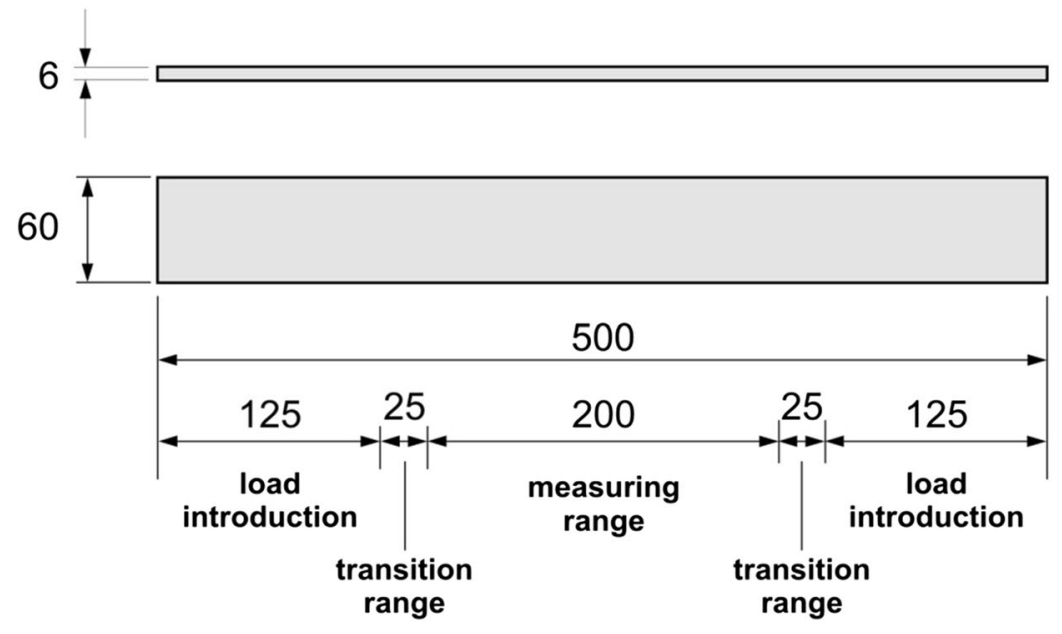

$[\mathrm{mm}]$

The pressure has to be adjusted so as to prevent slippage between the clam and the specimen. Optionally, hydraulic or pneumatic gripping with directly controllable clamping pressure can be used. Another optional extension is the usage of longitudinal bars providing the possibility to adjust the anchorage length independently of the clamp length as shown in (Fig. 3). This type of clamping is suitable for tensile tests of yarns with low bond to the matrix as mentioned before.

\subsection{Measuring devices}

The load can be measured with a standard load cell of proper capacity and accuracy. Deformations are measured on both surfaces in the middle of the specimen with devices of sufficient measuring range and accuracy.

\section{Test procedure}

\subsection{Preparation of specimens}

In the load introduction area, all overlapping concrete edges must be removed from the specimens. Local unevenness should be removed with a grinder.

Before testing:

- Specimen dimensions are measured as follows:

- Width at both ends of the measuring length, with an accuracy of $0.1 \mathrm{~mm}$;

- Thickness is measured at 4 points inside the measuring area, with an accuracy of $0.1 \mathrm{~mm}$. 
front view:

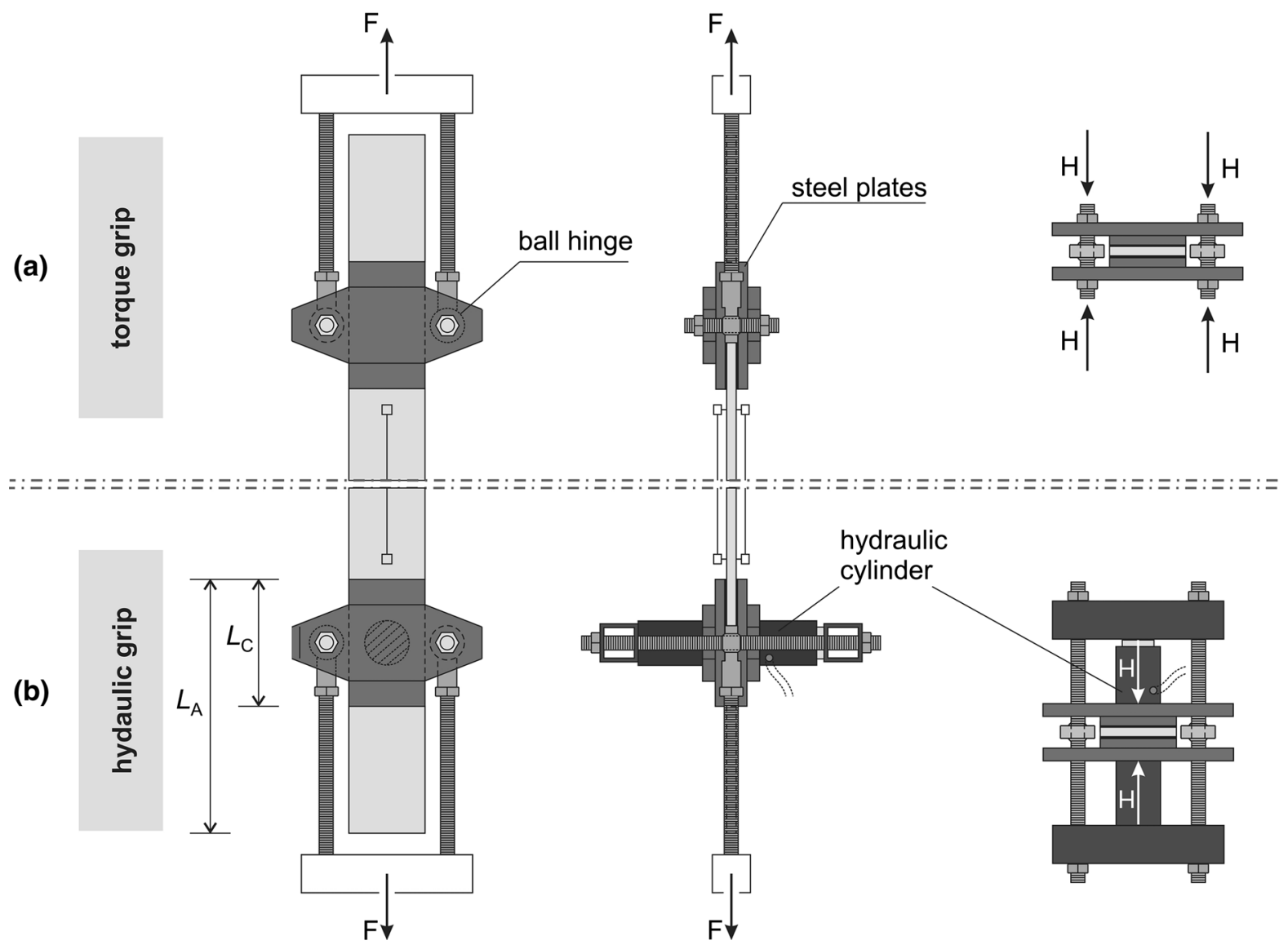

side view:

section: $=$
Fig. 3 Test setup [3]

- Length, with an accuracy of $1 \mathrm{~mm}$;

- Visible pre-damage (e.g. cracking, poor concrete quality) has to be documented.

- Deviations from prescribed specimen geometry and measures for elimination have to be documented, e.g. deviations from parallel reinforcement, uneven concrete surface, fibers in sawing cut, etc.

\subsection{Installation of specimens}

Specimens are mounted into the testing device. A thin sheet of rubber with a thickness between 0.3 and $1 \mathrm{~mm}$ has to be placed between the steel parts and the concrete specimen to avoid local load concentrations during the test. The specimen is preloaded with a force of $0.1 \mathrm{kN}$. Deformation measuring equipment is 


\subsection{Strain}

To determine the strain $\varepsilon$ of the tensile specimen, the measured deformations $\Delta l$ of the extensometer are averaged and then related to the measuring length $l_{\mathrm{m}}$. Maximum strain $\varepsilon_{u}$ is defined as strain at maximum $\operatorname{load} F_{\mathrm{u}}$.

\subsection{Stress}

For the determination of the stresses, the measured force $F$ is related to the cross-section of the specimen $A_{\mathrm{c}}$. If needed for design purposes, the force $F$ can also be related to the cross-section of the textile reinforcement $A_{\mathrm{f}}$.

or

Maximum stresses $\sigma_{\mathrm{cu}}$ and $\sigma_{\mathrm{fu}}$, respectively related to $A_{\mathrm{c}}$ and $A_{\mathrm{f}}$, is defined as stress at maximum load $F_{\mathrm{u}}$.

\section{Assessment of tensile test}

The tensile test is valid if the final crack occurs within the measurement length of the specimen. If not, the stress-strain relation is only valid up to the beginning of crack localization.

\section{Test report}

The test report shall include at least the following information:

- A reference to this test recommendation

- Origin and indication of the test specimens

- Origin, indication and material of the textile fabrics (including stiffness and cross-section, if known)

- Specimen dimensions (for accuracy see Sect. 7)

- Storage conditions (water temperature and air temperature in ${ }^{\circ} \mathrm{C}$, relative humidity in \%)

- Location/Position and number of textile layers

- Reinforcement ratio, if known

- Specimen age at the time of testing in days

- Anchorage length (and clamping length, if independent as indicated in Fig. 3)
- The level of lateral pressure imposed either using torque or using hydraulic or pneumatic gripping.

- Position of crack localization (free length/transition range)

- Mean crack spacing and if possible the crack pattern

- Stress-strain-diagram as a mean curve of all extensometers and if available, single curves

- If available, stress-strain response of textile roving indicating the stiffness of the reinforcement material giving an information on the achieved level of specimen's anchorage and, at the same time, on the utilization of the reinforcement material.

- Statistics

- Dimensions of the specimens (thickness, width, length) and averaged thickness and width;

- First crack stress, if recoverable;

- Type of failure (fiber rupture, fiber pull-out, others);

- Maximum load of the specimens and if possible the maximum stress referred to the cross sectional area and the area of textile reinforcement;

- Maximum strain of the specimens;

All the testing details that deviate from this recommendation have to be documented.

\section{References}

1. Brameshuber W (2006) RILEM; RILEM TC 201-TRC: Textile reinforced concrete. State-of-the-Art Report of RILEM Technical Committee 201-TRC. Bagneux : RILEM, 2006-Report 36 ISBN 2-912143-99-3

2. Jesse F, Schicktanz K, Curbach M (2009) Obtaining characteristic material strength of Textile Reinforced Concrete (TRC) from laboratory tests. In: Djausal A, Alami F, Naaman AE (ed.) 9th International Symposium on Ferrocement and Thin Reinforced Cement Composites (Ferro-9), 18-20 May 2009, Bali, Indonesia, pp 305-318

3. Scholzen A, Chudoba R, Hegger J (2015) Ultimate limit state assessment of TRC shell structures with combined normal and bending loading. In: Brameshuber W (ed.) 11th International Symposium on Ferrocexment and 3rd ICTRC International Conference on Textile Reinforced Concrete (Ferro-11), 7-10 June 2015, Aachen, Germany, pp 159-166 